\title{
Análise da sustentabilidade Ibiapaba no Ceará-Brasil em base ex post do planejamento regional
}

Este artigo objetiva demonstrar como as prioridades definidas nos planos de desenvolvimento foram contempladas nas dimensões da sustentabilidade em uma avaliação ex post. O locus da pesquisa é região da Ibiapaba, composta por nove municípios e teve por base os planos de desenvolvimento ao longo de 37 anos. Metodologicamente traz a abordagem exploratória e descritiva, qualitativa, com coleta de dados secundários e documental, o processamento da análise do planejamento regional se deu pelo IRAMUTEQ ${ }^{\circledR}$. Os resultados apresentam os termos destacados nas ocorrências: território f133, saúde f101 e turismo f95. A dimensão social foi prioritária, com demandas por saúde e educação. As dimensões ambientais veem os recursos naturais em prol da dimensão econômica no turismo e produção rural. A dimensão territorial preconiza a unificação regional. Considera-se que oito dimensões da sustentabilidade foram definidas nos planos desenvolvimento da Ibiapaba, sendo que nem todas estão em cada plano. Como também os nove municípios são citados nos planos, porém nem todos são contemplados em cada um deles. Ipu não é entendido como participante do território. Tianguá é o município sede regional, com distância econômica dos demais municípios.

Palavras-chave: Sustentabilidade; Dimensões da sustentabilidade; Planejamento regional; Avaliação ex post.

\section{Analysis of Ibiapaba of the Ceará-Brazil sustainability based on ex post regional planning}

This paper aims to demonstrate how the priorities defined in the development plans were considered in the dimensions of sustainability in an ex post evaluation. The research locus is a region of Ibiapaba, made up of nine municipalities and was based on development plans over 37 years. Methodologically it brings the exploratory and descriptive, qualitative approach, with secondary data collection and documentary, the processing of the regional planning analysis was given by IRAMUTEQ ${ }^{\oplus}$. The results present the terms given in the occurrences: territory $\mathrm{f} 133$, health $\mathrm{f} 101$ and tourism f95. The social dimension was a priority, with demands for health and education. The environmental dimensions see the natural resources in favor of the economic dimension in tourism and rural production. The territorial dimension advocates regional unification. As also, the nine municipalities are mentioned in the plans, but not all are contemplans in each one of them. Ipu is not understood as a participant in the territory. Tianguá is the regional headquarters municipality, with economic distance of the other municipalities.

Keywords: Sustainability; Dimensions of sustainability; Regional planning; Ex post evaluation.

\section{Topic: Planejamento Regional}

Reviewed anonymously in the process of blind peer.
Received: 09/05/2020

Approved: 07/06/2020
Cristiane Saboia Barros (iD)

Instituto Federal do Ceará, Brasil

http://lattes.cnpq.br/4891012984821498

http://orcid.org/0000-0002-1699-472X

cristianesaboia@hotmail.com

Júlia Elisabete Barden

Universidade do Vale do Taquari, Brasil

http://lattes.cnpq.br/2618070777171361

http://orcid.org/0000-0002-9818-1844

ibarden@univates.br

Ruan Carlos dos Santos (iD)

Universidade do Vale do Itajaí, Brasil

http://lattes.cnpq.br/8733116080978836

http://orcid.org/0000-0001-7396-8774

ruan santos1984@hotmail.com
Referencing this:

BARROS, C. S.; BARDEN, J. E.; SANTOS, R. C.. Análise da sustentabilidade Ibiapaba no Ceará-Brasil em base ex post do planejamento regional. Revista Ibero-Americana de Ciências Ambientais, v.11, n.4, p.474-491, 2020. DOI:

http://doi.org/10.6008/CBPC2179-6858.2020.004.0040 


\section{INTRODUÇÃO}

A sustentabilidade encaminhou-se a um constructo multidimensional, que contempla a existência das dimensões: social, econômica, ecológica, ambiental, territorial, cultural, políticas nacional e internacional (SACHS, 2009). Mesmo com a importância das dimensões propostas o autor considera três premissas para se estudar a sustentabilidade: consideração do local, a participação da sociedade civil no planejamento e as dimensões de sustentabilidade (SACHS, 1986a).

Nesta agregação de fatores condicionantes para sustentabilidade incluem à relevância da região e a participação popular neste processo. A expectativa de ascender uma região em escala de sustentabilidade faz-se necessária atividade específica como o planejamento, que por sua vez carecem de um escopo participativo e político, onde o centro da ação estaria na sociedade.

Em um contexto que aproxima estes requisitos, participação popular na construção de políticas públicas democráticas e apelo ambiental, apresenta-se o locus da pesquisa que é a região da Ibiapaba no Estado do Ceará. Considerada uma das 14 regiões administrativas do Estado do Ceará, permeada por nove municípios. Apontada como uma das regiões mais Antigas do Ceará habitada pelas tribos dos Tabajaras e Tapuias foi berço da colonização do Ceará. Do período colonial até hoje a região proporciona recursos naturais e é reconhecida como região e território que vão além de suas características geográficas, pela cultura, identidade e homogeneidade nas condições socioeconômicas.

Nos últimos quinze anos a região passou por políticas públicas estaduais e federais de planejamento regionais orientadas à sustentabilidade, podendo-se citar os planos de desenvolvimento sustentáveis ocorridos no período de 2002 a 2014, Plano de Manejo do Parque Nacional de Ubajara, Plano de Desenvolvimento Inter-Regional PDIR Vale do Coreaú Ibiapaba PDIR/2004, em escala estadual. O Plano de desenvolvimento Sustentável da Região Turística do Meio-Norte, PDSRT/2009, de escala federal. O Programa de Desenvolvimento do Turismo PRODETUR Ceará: manual de operações, 2012, em escala Estadual vem o Plano Territorial de Desenvolvimento Rural Sustentável em 2011, Plano Ibiapaba 2030, Rotas Estratégicas Setoriais 2030 e por fim o Plano de desenvolvimento integrado do turismo sustentável 2014, PDITS/2014, ambos estaduais.

Os planos regionais da Ibiapaba foram escolhidos por validarem as demandas locais de forma sustentável, que analisadas servirão de base para o acompanhamento e análise de seus resultados ao longo dos anos, desde a elaboração do primeiro plano regional. Nessa ótica, este estudo traz como discussão saber: em quais dimensões da sustentabilidade estão como prioridades definidas pelos planos de desenvolvimento, a partir de uma avaliação ex post? A necessidade de planejamento para uma região perpassa pela indicação de prioridades advindas da população e encaminhadas ao poder público como demanda a ser atendida. Partindo desse limiar, o objetivo desta pesquisa é demonstrar como as prioridades definidas nos planos de desenvolvimento foram contempladas nas dimensões da sustentabilidade em uma avaliação ex post.

O método de trabalho baseou-se em uma abordagem qualitativa-descritiva fazendo uso das técnicas de análise documental e por meio do uso software iramuteq. 0 estudo apresenta cinco seções: inicialmente 
a parte introdutória, a fundamentação teórica sobre as dimensões da sustentabilidade, planejamento e avaliação ex post, procedimentos metodológicos; a análise das dimensões da sustentabilidade da Ibiapaba no planejamento regional e conclusões.

\section{REVISÃO TEÓRICA}

\section{Aspectos seminais das dimensões da sustentabilidade}

A relação homem-natureza chega ao centro das discussões mundiais, buscando interação de forma equilibrada, fortemente influenciados pelas das formulações de Ignacy Sachs, onde o cuidado com o meio ambiente ultrapassa a sobrevivência apenas dos recursos naturais contempla a garantia da convivência de todos os fatores que compõem o meio, quer sejam bióticos, abióticos, humanos ou não-humanos e a garantia de sobrevivência desta e das próximas gerações.

Elevando a sustentabilidade a um nível de complexidade, amplia-se a análise em uma visão macroscópica e interdisciplinar, e de forma progressiva vem tomando credibilidade e utilidade para planejamento de políticas públicas. A sustentabilidade deve que contribuir para o desenvolvimento social, orientando as atividades à coerência, a transparência, de forma multidimensional englobando a economia, a ecologia e a política ao mesmo tempo (CHEN et al., 2014).

O conceito de sustentabilidade é constructo amplo, que tenderia de acordo com o caminho da pesquisa a que se recorre, seja voltada à economia e manutenção da longevidade do sistema econômico capitalista, seja na percepção radical da ecologia. Encontrar soluções tecnológicas para a otimização dos recursos naturais. A inter-relação entre as ciências econômicas, ambientais, sociais abrem a possibilidade para a almejada sustentabilidade, seja algo a ser conquistado ou a condição para a sobrevivência humana. Tendo nas dimensões a capacidade definir as condições de sustentabilidade a serem contempladas. Visto que o conceito de desenvolvimento sustentável é o que tem capacidade de perdurar ao longo do tempo, e o desafio é incorporar estre conceito ao processo de planejamento do Nordeste (MAGALHAES, 1994).

A sustentabilidade sendo uma abordagem multidimensional, multidisciplinar e sistêmica incorpora a capacidade dinâmica de adaptação do planeta a partir de condições econômicas, físicas, biológicas, geológicas, químicas e a natureza define um limite existente, como uma forma de restrição das atividades societais, aspectos: políticos, sociais, culturais, físicos, harmonia social, questões de cidadania, valores éticos e morais (STAHEL, 1994).

É possível aceitar o desafio, há viabilidade em encontrar alternativas razoáveis para o progresso da humanidade. Bens não essenciais têm custos marginais elevados e aumentam a entropia, a percepção multidimensional da sustentabilidade proporciona mais precisão em apresentar os resultados do esforço coletivo de mitigar os impactos ao ecossistema. Ao se consultar diversas como as ciências econômicas, antropológicas e etnociências, para explicar sustentabilidade, compreendem-se padrões do consumo e de comportamentos em sociedade, sendo possível adapta-los (CAVALCANTI, 2012).

Nascimento (2012) também traz questionamento, sobre o significado e a suficiência das três 
dimensões para a sustentabilidade, econômica, ambiental e social. Mesmo reconhecendo a importância de cada uma delas, a dimensão ambiental e sua discussão sobre o ecossistema e sua capacidade de autoreparação e resiliência. A econômica com a contínua busca pela inovação tecnológica com eficiência no consumo de recursos naturais para a produção. A dimensão social em estabelecer o mínimo e o máximo necessário a uma vida digna e a atendimento da justiça social. Reflete que o problema está em escolhê-las como essencial, excluindo-se dimensões como o poder e a cultura.

Magalhaes (1994) destaca quatro dimensões, corroborando com Nascimento (2012) inclui a dimensão política, para o desenvolvimento sustentável, sendo as quatro dimensões: econômico, social, ambiental, político. $O$ econômico trata da capacidade dos empreendedores gerarem adquirirem sustentação econômica; A Social diz respeito a reduzir desequilíbrios sociais; A ambiental diz respeito às necessidades de conservação da natureza e a dimensão política que trata a estabilidade dos processos decisórios e das políticas de desenvolvimento. Sugere ainda, na mesma linha de Nascimento a possibilidade de inclusão da dimensão cultural, mas no entendimento de preservação dos valores e suporte as transformações sociais e econômicas mantendo suas identidades. E reconhece como simplificado as dimensões abordadas, mas justifica que contempla vários ingredientes comuns às definições de desenvolvimento sustentável.

Para Sachs (1986a) a essência do desenvolvimento seria o desenvolvimento endógeno, argumentando a capacidade interna do país em aproveitar suas potencialidades e gerar evolução econômica, característica fortemente vinculada aos países do terceiro mundo, o desenvolvimento partiria da promoção da partilha equitativa do ter. Enquanto conceito de ecodesenvolvimento é colocado no centro do desenvolvimento 'trata-se de gerir a natureza de forma a assegurar aos homens de nossa geração e a todas as gerações futuras a possibilidade de se desenvolver'. A adoção do termo ecodesenvolvimento voltar-se-ia à mudança social, no estilo de vida, visão de futuro, ratificando o fim social para o desenvolvimento, seria uma fase de construção conceitual e para a posterior definição de desenvolvimento sustentável para Sachs.

A posteriori Sachs (1993) desenvolve as cinco dimensões de sustentabilidade do ecodesenvolvimento, sustentabilidade: social, econômica, ecológica, espacial e cultural. Apresenta-nos os três pilares do ecodesenvolvimento com "o atendimento simultâneo dos critérios de relevância social, prudência ecológica e viabilidade econômica", amadurecendo seu modelo a nove dimensões: social, cultural, ecológica, ambiental, territorial, econômica, política (nacional e internacional) (SACHS, 2009)

A partir desta compreensão vem-se o desafio de como dimensionar a sustentabilidade, por ser uma composição interdisciplinar adotam-se o modelo de multicritérios ou multidimensional, dispõem-se como eles de parâmetros que possibilitam avaliação e a construção agendas globais e projetos locais e globais para atender as condições de longo prazo da sustentabilidade.

\section{Monitoramento do planejamento institucionalizado}

Há fatores para o planejamento e avaliação de planos públicos que devem ser considerados. Brose (2014) diferencia a administração pública e a gestão empresarial onde, segundo ele, a complexidade está nos problemas contraditórios, ou intratáveis que o poder público vai ao enfrentamento, que são como sistemas 
sociais abertos, descritos como difíceis de identificar e descrever, não possuem solução, pois dependem de um grande número de pessoas, em constante transformação e são problemas profundos.

Silveira et al. (2013) levam a reflexões sobre a elaboração de um planejamento público, sobre a escolha da metodologia e a enfatizam que de acordo com os princípios assumidos pode ocorrer descompasso entre o que se pretende e o que se projeta. Na definição do diagnóstico e visão de futuro se pode mostrar a disposição dos agentes de planejamento em incorporar, ou não, os princípios metodológicos definidos a priore. Mesmo com as várias escolas de planejamento Diniz (2009) e Silveira et al. (2013) defendem que os processos de planejamento públicos no Brasil estão muito focados em programas de desenvolvimento normativo, podendo-se citar o modelo de desenvolvido no âmbito da Cepal.

Segundo os autores, o que se pode considerar como a base do planejamento eleito pela Cepal era o modelo normativo, racional e desenvolvimentista de origem na Universidade de Chicago que consistia no modelo genérico rational planning de Banfield, destinado aos países capitalistas democráticos, que incluía ideias das ciências sociais e econômicas. Seriam descritos de forma simplificada como os cinco 'D': '(...) desires, design, deduction, decision and deed' (desejos, projeto, dedução, decisão e ação) sendo este o modelo mais adequado para superação dos problemas latinos.

Neste modelo de planejamento as metas vêm de forma racionalizada e visam a otimização de recursos, relação de custo benefício econômico, consideram o comportamento social como previsível por meio de modelo analítico, com diagnóstico feito a partir da análise do comportamento histórico. Além desta percepção bastante crítica, argumentam ainda que nesta escola a visão de futuro estático e passivo, com o planejador como fator central do processo, sendo o detentor de poderes.

As metas são requisitos que num processo de planejamento que auxiliam na explicação, quantificação e mensuração das demandas e que posteriormente subsidiarão num processo avaliativo. Dada a relevância dos indicadores garantem transparência e podem ser vistos como parâmetros de consulta, para demonstrar ajustes necessários (REIS, 2013; ARAÚJO SOBRINHO et al., 2015);

$\mathrm{Na}$ avaliação de resultados e impactos sociais, tudo deve ser considerado, até mesmo riscos mais 'brandos' como dizem Arce-Gomez et al. (2015), como quais quer impactos negativos sobre a cultura da comunidade e não podem ser negligenciados, os impactos sociais podem e ocorrem independentemente do biofísico ou fatores ambientais e cabe a avaliação entender as implicações e efeitos de cada um deles.

Para um plano de monitoramento os autores instruem que se deve ter claramente metas e resultados esperados, impactos sociais a serem monitorados e quem deve monitora-los, quantidade e frequência de monitoramento, indicadores de desempenho que permitam o monitoramento de forma clara para a compreensão de todos os grupos de interessados, mantendo assim o controle do impacto e a intervenção planejada (MALHEIROS et al., 2008)

\section{Avaliação ex post}

A avaliação ex post caracteriza-se por um modelo de intervenção de verificação no desenvolvimento do projeto, Chou et al. (2016) orientam que o projeto tenha sido concluído há mais de ano, outro aspecto é 
a questão da utilidade, que vai além da mensuração de resultados, pode ser vista como uma ferramenta de resolução de problemas de forma proativa, pois determina as lições aprendidas que podem vir a orientar a gestão dos projetos no futuro.

Apresenta uma metodologia adequada à avaliação das políticas de desenvolvimento local e que possibilitam melhorar a intervenção pública e verificação do rigor e coerência dos planos públicos em suas execuções, garantindo a possibilidade de não ocorrerem os mesmos erros do passado. Pois deter ferramenta de avaliação é fator chave para mensurar a concretização de planos de desenvolvimento. Este modelo de análise, o ex post, considera também a natureza das intervenções relacionadas ao desenvolvimento urbano e infraestrutura social, e sua metodologia está baseada em dados de monitoramento, rastreamento de documentos, entrevistas com as autoridades de gestão (HAMZA et al., 2016)

Estas avaliações baseiam-se em informações coletadas sobre as políticas já implementadas (com base em percepções e ações dos agentes políticos locais e centrais e de chave com bases nas seguintes etapas: avaliação da pertinência (relação de metas para os problemas); a avaliação da coerência (relação de recursos para metas); a avaliação da eficiência (relação de ações para recursos); avaliação de eficácia (relação de impactos de ações). Tendo como prioridades avaliar as metas, recursos, ações e impactos (POMPILI, 1996).

Chou et al. (2016) usaram o seguinte grupo de categorias: quadro institucional, o desenvolvimento sustentável: economia, sociedade e meio ambiente e gestão dos recursos do projeto, custo e tempo. E enfatizam que a avaliação ex post é um modo de avaliação que identifica os fatores que contribuem para o sucesso ou fracasso de um projeto.

Dentre os itens avaliados em uma avaliação ex post podem-se citar: a abordagem estratégica, as realizações, a sustentabilidade financeira dos projetos, os indicadores, os fatores de sucesso identificados e as perspectivas de futuro (HAMZA et al., 2016). E as tarefas do avaliador são claras neste processo: identificar objetivos, para traduzi-las em sucesso mensurável indicadores, para coletar informações sobre os beneficiários de política e um grupo de não beneficiários de controle (POMPILI, 1996; CARR et al., 2015).

Percebe-se a possibilidade em analisar planos de desenvolvimento que se encontre eixos prioritários interligados, mas que estratégia de desenvolvimento urbano ou de infraestrutura social esteja raramente expressa explicitamente, muitas vezes está combinada com outras questões, como também os programas são abstratos, imprecisos, formulações vagas, sem interligação e com programas guarda-chuva para englobar várias áreas como o desenvolvimento sustentável e melhoria das cidades e áreas urbanas (HAMZA et al., 2016).

\section{METODOLOGIA}

A Região da Ibiapaba se localiza ao norte do Estado do Ceará, agrupa nove municípios, são eles: Carnaubal, Croatá, Guaraciaba do Norte, Ibiapina, Ipu, São Benedito, Tianguá, Viçosa do Ceará, Ubajara. A área territorial $\left(\mathrm{km}^{2}\right)$ é de 5.697,30, com 357.080 habitantes. A média do IDH Regional foi de 0,63 em 2010. O PIB per capita de $R \$ 10.625$, sendo que $65,86 \%$ dos domicílios tinha renda mensal per capita inferior a $1 / 2$ salário mínimo, 2010, percebendo-se com estas últimas variáveis a concentração de renda em uma parcela 
da população. O IDEB I foi de 5,6 e o II foi de 4,5 em 2015. A mortalidade infantil foi de 13.92/mil (IPECE, 2016). Para esta pesquisa regional tomou-se como base objetivo e fim exploratórios e descritivos, de abordagem qualitativa, a partir dados secundários. Por fim, como resultado tem-se a natureza aplicada (RAUPP et al., 2006, LAKATOS et al., 1992).

A coleta documental dos planos regionais se deu em órgãos de esferas municipal, estadual e federal quaisquer documentos relacionados ao planejamento regional da Ibiapaba. A primeira instituição consultada foi o Conselho de Desenvolvimento da Ibiapaba - CONDERI. A partir dele e por meio de cadeia de referências, no modelo em bola de neve, se chegaram a outras instituições para ter acesso a todos os documentos regionais.

Como universo foram identificados a elaboração de 10 (dez) documentos de planejamento regional, ao longo dos últimos 37 anos. Foram adotados os seguintes critérios de exclusão entre os dez planos disponíveis. Foram excluídos três documentos que foram retirados do universo da pesquisa por busca-se um recorte temporal deste século, os documentos de características apenas de diagnóstico setorial e os que pontuaram apenas uma ação relacionada a região.

Após a aplicação dos critérios de inclusão sete documentos de planejamento regional foram selecionados, os quais foram chamados de textos, porém somente seis textos estavam disponíveis, seja de forma impressa ou digital, no documento intitulado 'Ibiapaba 2030' de elaboração da Secretaria das Cidades não estava disponível em nenhuma plataforma. Foram eles: 1) o Plano de Manejo do Parque Nacional de Ubajara, em seu encarte 6 - Planejamento, construído em 2002, 2) PDIR/2004, vem de escala Estadual, 3) PDSRT/2009, de hierarquia federal, 4) PTDRS/2011(Território Serra da Ibiapaba), 5) PRODETUR/2012, estadual e o 6) PDITS/2014, também estadual.

A pesquisa iniciou pelas definição as questões e objetivos, assuntos-chaves e questões principais; foram constituídos de corpus textuais, que são conjuntos de textos elaborados pelo pesquisador, com conceitos, as dimensões e a descrição teórica sobre a sustentabilidade que serviram de base para a busca de similaridade estatística nos planos de desenvolvimento, construída no software IRAMUTEQ ${ }^{\circledR}$ (Interface de $R$ pour analyses Multidimensionnelles de Textes et de Questionneires, versão 0.7), software gratuito e de fonte aberta desenvolvido por Pierre Ratinaud (RATINAUD et al., 2012).

O software IRAMUTEQ utiliza a estrutura R (www.r-project.org) para realização dos cálculos estatísticos e permite realizar análises quantitativas e qualitativas de dado textuais por meio de lexicografia (frequência e estatística básicas) (CAMARGO et al., 2013).

Após a análise dos planos de desenvolvimento da região da Ibiapaba em que foram extraídas as prioridades coletivas dos documentos chamados de planejamento regional, estes itens foram estabelecidos paralelos entre as prioridades encontradas e as dimensões da sustentabilidade da Ibiapaba. Em seguida constituiu-se, das coletas dos dados secundários nas prefeituras e nos órgãos oficiais locais, para identificação de realizações relacionadas às prioridades definidas nos planos de desenvolvimento da Ibiapaba.

As análises seguem a partir das construções qualitativas obtidas por meio das elaborações do corpus, 
que geraram resultados estatísticos a partir do software. Foram analisadas nestas seções foram gerados o corpus I, como também o corpus II e corpus III, as tabelas das Classificação Hierárquica Descendente (CHD) e delas definem-se o modelo de indicadores para a Ibiapaba.

O corpus I - 'Segmento humano e ambiental' agrupa trechos de cinco textos, e os elementos que o compõe versam sobre aspectos relevantes para o desenvolvimento e garantia da sustentabilidade. Seções como 'infraestrutura elétrica, hídrica e de estradas', 'ambiente natural', 'aspectos antrópicos', 'aspectos de saúde', 'dimensão sociocultural educacional', entre outros, são alguns exemplos de elementos que compõe esse corpus.

O corpus II - 'territorialidade e política' há elementos dos seis textos. Seções como 'planejamento por área de atuações', 'planejamento, ordenamento e gestão ambiental e territorial', 'arranjo institucional para execução do programa', são exemplos de elementos desse corpus.

O corpus III - 'planejamento' congrega elementos dos textos que versam sobre o processo de planejamento da execução dos planos. Os seis textos estão presentes nesse compus, por meio de seções como: 'planejamento por área de atuação', 'área de abrangência do plano', 'modelo de gestão do plano', 'metodologia para elaboração das estratégias e planos de ação de desenvolvimento turístico', entre outras.

Por fim, o corpus IV - 'elementos neutros' agrega os elementos 'que' não pareciam, a princípio, se aproximarem teoricamente com os outros corpora. Esse corpus é composto por seções como 'zoneamento', 'organismos envolvidos com o programa', 'análise da capacidade de carga'.

Obteve-se como produto a Figura 1, com os indicadores do dendê grama de classes (que representam os corpora), além destes resultados foram obtidas análises de similitude, classificação hierárquica descendente (CHD) no decorrer da análise. A análise de Similitude foi baseada na teoria dos grafos (RATINAUD et al., 2012), permite a identificação das coocorrências entre as palavras, e a CHD analisa qual dos segmentos do texto são classificados em função dos seus respectivos vocabulários, e o conjunto deste é repartido em função da frequência das formas reduzidas.

\section{RESULTADOS}

\section{Dimensões da Sustentabilidade da Ibiapaba no Planejamento Regional}

O resultado do processamento dos seis textos (planos de desenvolvimento da Ibiapaba) possui 74.656 ocorrências, 6.749 formas, 2.835 hapax (palavras que aparecem apenas uma vez no corpus), gerando uma média de 14.931,20 palavra por texto. Com o intuito de conhecer a estortura subjacente do corpus procedeu-se com a classificação hierárquica descendente. Para essa análise foram considerados 1.965 dos 2.156 (91,14\%) dos seguimentos de texto do corpus, com média de 34,62 ocorrências por seguimento, satisfazendo os critérios apontados pela literatura para a realização desta análise (CAMARGO et al., 2013). A presentasse a Figura 1 com o Dendograma de Classes descritas as prioridades da Ibiapaba. 


\begin{tabular}{|c|c|c|c|c|c|c|c|c|c|c|c|c|c|c|}
\hline \multicolumn{3}{|c|}{\begin{tabular}{|c|} 
Classe 5 \\
$435 / 1965$ Seg. Texto $22,14 \%$
\end{tabular}} & \multicolumn{3}{|c|}{$\begin{array}{c}\text { Classe } 4 \\
465 / 1965 \text { Seg. Texto } 23,66 \%\end{array}$} & \multicolumn{3}{|c|}{$\begin{array}{c}\text { Classe 1 } \\
480 / 1965 \text { Seg. Texto } 24,43 \%\end{array}$} & \multicolumn{3}{|c|}{$\begin{array}{c}\text { Classe 3 } \\
288 / 1965 \text { Seg. Texto } 14,66 \%\end{array}$} & \multicolumn{3}{|c|}{$\begin{array}{c}\text { Classe 2 } \\
\text { 297/1965 Seg. Texto 15,11\% }\end{array}$} \\
\hline Palavra & f. & $x^{2}$ & Palavra & f. & $x^{2}$ & Palavra & f. & $x^{2}$ & Palavra & f. & $x^{2}$ & Palavra & f. & $x^{2}$ \\
\hline Saúde & 101 & 249,26 & Turistico & 95 & 269,84 & Territorial & 63 & 149,9 & Serra & 83 & 212,49 & Guaraciaba & 76 & 370,29 \\
\hline Ensino & 55 & 164,61 & Polo & 72 & 183,26 & Açào & 81 & 135,28 & Anuário & 38 & 210,71 & Norte & 72 & 304,69 \\
\hline Educação & 64 & 98,9 & Uso & 48 & 115,54 & Desenvolvimento & 92 & 129,12 & Estatistico & 38 & 203,81 & Camaubal & 62 & 257,6 \\
\hline Atenção & 34 & 93,61 & Suficiente & 42 & 110,99 & Público & 98 & 122,68 & Ipece & 34 & 161,52 & Tianguá & 80 & 254,92 \\
\hline Atendimento & 36 & 86,08 & Quesito & 35 & 109,84 & Politico & 62 & 121,43 & Território & 133 & 154,97 & Benedito & 76 & 250,68 \\
\hline Escolar & 27 & 81,4 & Atividade & 62 & 106,79 & Gestão & 61 & 121,32 & Fonte & 66 & 153,18 & Croatá & 60 & 228,9 \\
\hline Básico & 51 & 75,76 & Natural & 41 & 103,87 & Sociedade & 40 & 116,57 & Ano & 69 & 130,74 & Viçosa do Ceará & 53 & 221,38 \\
\hline Familia & 51 & 73,89 & Turismo & 58 & 97,7 & Programa & 73 & 100,9 & Ceará & 78 & 103,31 & Ubajara & 73 & 216,75 \\
\hline Sus & 22 & 72,97 & Restrição & 32 & 90,59 & Social & 89 & 90,42 & Ibiapaba & 89 & 96,89 & Ibiapina & 59 & 187,04 \\
\hline Infantil & 27 & 65,85 & Conservação & 39 & 83,85 & Civil & 34 & 84,88 & Homem & 16 & 86,56 & Ii & 37 & 119,98 \\
\hline Fundamental & 32 & 64,08 & Solo & 29 & 80,74 & Governo & 38 & 79,86 & Rebanho & 12 & 70,3 & Micro & 42 & 94,97 \\
\hline Idoso & 19 & 57,51 & Regiầo & 58 & 68,76 & Articulaçào & 25 & 78,34 & Classe & 12 & 63,08 & Tabajara & 13 & 73,5 \\
\hline Pessoa & 32 & 50,09 & Ocupação & 23 & 65,46 & Participação & 37 & 76,9 & Causa & 21 & 58,57 & Ipu & 18 & 72,33 \\
\hline Tratamento & 14 & 49,59 & Patrimb̂nio & 25 & 63,74 & Municipal & 62 & 75,32 & Municipios & 14 & 57,87 & Localizar & 18 & 67,91 \\
\hline Salário & 15 & 47,99 & Sinalização & 19 & 61,89 & Projeto & 63 & 72,75 & Figura & 15 & 54,7 & Padre & 10 & 56,45 \\
\hline Minimo & 17 & 46,32 & Agricola & 26 & 59,72 & Estadual & 39 & 61,55 & Município & 108 & 53,92 & Indigena & 16 & 53,78 \\
\hline Jovem & 17 & 46,32 & Grande & 40 & 57,15 & Conselho & 26 & 60,29 & Cabeça & 9 & 52,65 & Indio & 12 & 49,6 \\
\hline Criança & 21 & 46,05 & Área & 63 & 55,15 & Colegiado & 20 & 57,66 & Conceder & 9 & 52,65 & Vila & 8 & 45,11 \\
\hline Nasf & 13 & 46,03 & Visitante & 17 & 50,38 & Organização & 29 & 51,11 & Percentual & 24 & 51,03 & Domicilio & 12 & 41,13 \\
\hline Situação & 37 & 45,6 & Atrativo & 20 & 47,89 & Secretaria & 35 & 51,09 & Milhào & 20 & 46,79 & Acaraú & 7 & 39,45 \\
\hline Especializado & 12 & 42,47 & Bom & 26 & 47,87 & Elaboração & 28 & 50,93 & Aparelho & 9 & 45,61 & Sede & 11 & 36,17 \\
\hline Beneficio & 22 & 41 & Ambiental & 46 & 46,98 & Processo & 40 & 50,15 & Consumidor & 10 & 45,53 & Tupi & 6 & 33,8 \\
\hline Deficiência & 17 & 39,24 & Produto & 29 & 44,47 & Agrário & 16 & 49,91 & Produção & 31 & 44,36 & Tapuia & 6 & 33,8 \\
\hline Odontológico & 11 & 38,91 & Passageiro & 12 & 38,95 & Politica & 29 & 48,63 & Verificar & 19 & 42,61 & Aldeia & 6 & 33,8 \\
\hline Portador & 11 & 38,91 & Classificar & 16 & 38,93 & Atuação & 22 & 48,27 & Responder & 11 & 41,61 & Senhor & 7 & 32,8 \\
\hline
\end{tabular}

Figura 1: Dendograma de classes do corpus 'Nome do corpus dos indicadores'.

Na análise de similitude da Classe 5 é possível observar a centralidade da comunidade organizada pela palavra 'saúde', ligam-se a ela as comunidades 'população', 'condição', 'atendimento', 'situação', 'atenção' e 'social', entre outras. Destacam-se outras comunidades que indicam a presença de outras políticas públicas, como a comunidade 'social', ligada à comunidade 'família', que agrupa informações relacionadas a política de assistência social, tanto no âmbito da proteção social básica como na especial. Para a comunidade 'educação' que se liga as comunidades 'formação' e 'ensino', indicando questões relativas a educação de crianças jovens e adultos, bem como a quantidade e estrutura das escolas.

A Classe 4 agrupa 465 dos 1965 seguimentos de texto (23,66\%), e as palavras que apresentam maior associação com a classe são referentes às atividades de turismo e a conservação do meio ambiente. $\mathrm{Na}$ análise de similitude a comunidade está organizada em torno do verbete 'turístico' em uma posição central no grafo, a ela se ligam comunidades organizadas pelas palavras 'turismo', 'plano', 'existir', 'polo', 'atividade', entre outras. No lado esquerdo à comunidade 'atividade' ligam-se 'urbano', 'região', 'serviço' e 'produção', na parte superior à comunidade 'polo' liga-se a comunidade 'Ibiapaba', 'quesito'. No canto direito inferior à comunidade 'plano' se liga a comunidade 'área', que por sua vez é ligada a 'uso'.

A Classe 1 agrupa 480 dos 1965 seguimentos de texto (24,43\%), e as palavras que apresentam maior associação com a classe são referentes gestão da máquina pública nas suas mais distintas formas. $A$ análise de similitude não apresenta uma comunidade centralizada no grafo, indicando que o sentido dessa pode estar difuso. Nota-se a conexão da comunidade "desenvolvimento" com "programa", "plano", "territorial" e "social", que por sua vez se liga a "público", quer por sua vez se liga a "municipal” e a "ação". A divisão inicial em dois subcorpus indica que os mesmos apresentam sentindo distantes, ou até mesmo opostos.

A Classe 3 agrupa 288 dos 1965 seguimentos de texto (14,66\%), e as palavras que se associam a elementos técnicos da construção dos planos. A análise de similitude se organiza em torno do verbete 
'território' ocupa a posição central no grafo, ligando-se a 'município', 'doença', 'ano', 'produção', 'total', 'Ceará' e 'Ibiapaba'. A comunidade 'ibiapaba' apresenta palavras que indicam elementos da produção econômica, como 'hospedagem', 'bovino', 'suíno' entre outras, a comunidade 'município' também apresente elementos que indicam um sentido semelhante, parecendo se diferenciar no tocante a elementos ligados ao comércio. A Classe 2 agrupa 297 dos 1965 seguimentos de texto (15,11\%), referenciam-se a localidades da Ibiapaba. A análise de similitude é a conexão da comunidade 'município' com duas outras, 'Tianguá' e a segunda por 'Guaraciaba'. Trazem a indicação de aproximação desses municípios.

Os planos regionais da Ibiapaba foram parâmetros para análise das dimensões da sustentabilidade por considerar a visão de Sachs (1993) que defende a necessidade de "boas doses de planejamento estratégico" para o desenvolvimento. Considera-se que as oito dimensões para a sustentabilidade de Sachs (2009) foram definidas para o desenvolvimento da Ibiapaba, sendo que nem todas as dimensões da sustentabilidade foram pontuadas em cada plano.

\section{DISCUSSÃO}

\section{Dimensões da Sustentabilidade da Ibiapaba}

\section{Dimensão social e econômica}

A dimensão social está presente universalmente nos dentre as categorias que compõem o modelo de sustentabilidade multidimensional. Estão citados como requisitos para esta dimensão as condições básicas para manutenção da vida e questões de cidadania na busca por mitigar desigualdades sociais (STAHEL, 1994; CAVALCANTI, 1994; 2012; CHEN et al., 2014).

Tomando-se como centro da dimensão a equidade social, distribuição de renda, acesso aos serviços básicos e as condições mínimas e máximas para o bem-estar, traz-se a análise deste pressuposto básico da sustentabilidade na Ibiapaba, com a análise das demandas apontadas no planejamento regional que se refere ao bem-estar humano, concentradas em saúde, educação e os programas sociais de proteção humana (SACHS, 1993; 2000; 2009).

O termo mais significativo entre todas as classes, o termo de maior destaque é 'NASF' que aparece em quatro das dez construções de frases, por meio da associação da palavra à classe 5 , que pode ser traduzido, devido ao foco estar relacionado à saúde, aos Núcleos Ampliado de Saúde da Família (NASF-AB) foram também citados 'PSF', o Serviço Único de Saúde o 'SUS', as siglas que também tiveram destaque 'CEO' e 'SAMU'.

Esta representação demonstra consciência local sobre as necessidades e as etapas preconizadas para o funcionamento adequado pelo SUS, seja ao perceberem seus direitos, seja na a atenção básica em atividades preventivas com a atividade física, ampliação de equipes de saúde da família para acompanhamento da criança e da mulher, núcleos e unidades de saúde, primeiros socorros, níveis secundário e terciário, indo até aplicação de recursos e controle.

A situação de atendimento de saúde considera-se que o parâmetro não está adequando, onde 
apenas $62,5 \%$ teria cobertura de núcleo de saúde da família, no item 'o atendimento do requisito médico por habitante na região' está de acordo com as recomendações da OMS. A segunda prioridade, a educação se apresenta em conjunto com infraestrutura, ciência e tecnologia, esgotamento sanitário com 97,64 de associação. As relações da educação estão na recorrência da necessidade de ampliação do ensino superior e implantação de uma universidade regional, que por sua vez se relaciona com a dimensão econômica ao ser citado 'ciência e tecnologia' e na associação 16,48.

No espectro sustentabilidade, a educação tem destaque por ser uma questão emancipadora, capaz de encaminhar às mudanças políticas, culturais e econômicas, partindo de uma questão central a mitigação das desigualdades sociais. Dentre seus princípios básicos para o desenvolvimento estão a participação da população envolvida e os programas de educação. Estaria como uma condição para a liberdade humana, proporcionando condições para o discernimento e a participação popular e um processo democrático. Ainda na tecnologia, seja nas condições para transferência tecnológica ou criação de valor agregado ao produto local (SACHS, 2000; 1986b)

A análise de similitude da Classe 3, com foco na dimensão econômica destaca-se a relação com a economia local que são as cooperativas, 'atualizadas pelos comitês de educação e cultura, rural, cooperativas'. As cooperativas detêm uma condição significativa no meio rural da Ibiapaba, são 12 cooperativas na Ibiapaba, cinco trabalham na produção agrícola e agropecuária, uma de guia turismo no Parque Nacional, duas de eletrificação rural, uma de crédito financeiro e uma de saúde, transporte alternativo e turismo. Geograficamente, seis delas tem sede em Tianguá. A Cooperativa Agropecuária dos Produtores Orgânicos - Coapoi, por sua vez funciona em Guaraciaba do Norte, desde os anos 2000 e conta hoje em 2018 com 31 pequenos agricultores de hortaliças e frutas.

A Classe 3 centralizada por 'território' traz as relações que trazem sentido ao grupo estão infraestrutura como energia, rotas para escoamento da produção rural, para a geração de emprego e renda, e indicadores e processos de planejamento que favorecem a visualização da realidade local por meio de seu território.

O fornecimento elétrico é uma condição para as dimensões da sustentabilidade social e econômica, em prol de melhores condições de vida e para a dimensão econômica, a diversidade da matriz energética em conjunto com a capacidade de atendimento e expansão de uma rede elétrica que forneça melhores oportunidade de produção para o agronegócio local fomentaria mais a renda, com inovação, tecnologia, para empregos de maiores valores agregados (SACHS, 2009).

\section{Dimensões territorial e cultural}

A dimensão territorial apresenta-se na avaliação de indicadores de saúde para o território e no agrupamento dos municípios. Na Classe 5, com 72,98 de associação e reivindicam melhores condições de saúde para a zona rural, buscando eliminação das disparidades inter-regionais (SACHS, 2009).

Dentre as palavras de maior ocorrência dos indicadores do dendograma de classes, estão 'território' com f133 ('f' é frequência, é quantidade de vezes que a palavra apareceu na classe) seguido por 'município' 
f108, 'saúde' com f101, e 'turístico' com f95.

$\mathrm{Na}$ análise descendente da Classe 2, com x²310,86 e segundo segmentos de texto com x² 295,14 o foco está nos municípios de Guaraciaba do Norte (por duas vezes, apenas nos dois primeiros segmentos de texto). Os municípios de Carnaubal, Tianguá e São Benedito estão logo nestes dois segmentos permanecem presentes. Tianguá por seis vezes, Carnaubal por cinco vezes, São Benedito por quatro vezes. Ubajara e Croatá estão citados por duas vezes nos últimos segmentos de texto e Viçosa do Ceará aparece por uma vez no penúltimo segmento.

A interpretação para o município de Guaraciaba do Norte aparecer no primeiro segmento de texto em aderência à classe relaciona-se à aspectos da sustentabilidade ecológica e ambiental. Guaraciaba do Norte destaca-se por ser o primeiro município Cearense com selo ADAO pela produção de orgânicos nos moldes de negócios agroecológicos, ter solos recuperados que atendem as necessidades nutricionais das plantas, resultados ecológicos em uma iniciativa de quase 20 anos, a partir da criação da Cooperativa Agropecuária dos Produtores Orgânicos - COAPOI (SACHS, 2009; SERAFIM, 2008).

Tianguá, dentre suas características estão: é município polo da região, possui a maior população, maior receita da arrecadação de ICMS, maior PIB per capita, tem o melhor índice de IDHM da região, classificando-se no ranking do estado do Ceará na posição 18으, enquanto os demais municípios estão todos acima da posição 75․ Além de localização privilegiada na principal via de acesso a Ibiapaba por meio da BR 222 aglomera os serviços públicos, que alavanca ainda mais a liderança de Tianguá na região. Poder-se-ia pensar em segmentar os serviços por municípios como uma forma de interiorizar os serviços dentro do eixo da Ibiapaba, de modo a favorecer a sustentabilidade regional (OLIVEIRA et al., 2010).

Nos últimos segmentos aparecem os municípios de Croatá, Ubajara e Viçosa do Ceará. Deste três Croatá sendo o único município serrano que não compõem a Rota Turística Mirantes da Ibiapaba, segundo o IPETURIS (2011) o município de Croatá não dispõe de atrativos turísticos relevantes.

Ubajara e Viçosa do Ceará aparecem com número reduzido de termos, e este remete ao século XVII, as relações com impactos ambientais e a dimensão cultural. Ubajara é o município com principal atrativo turístico do complexo Ibiapabano, o Parque Nacional de Ubajara, envolto de composição histórica, natural e lendas indígenas. Os fatores culturais interferem na comunidade, geram impactos sociais e cabe a avaliação entender as implicações e efeitos de cada um deles (ARCE-GOMEZ et al., 2015).

O parque nacional de Ubajara se enquadra na categoria de Unidade de Proteção Integral, com posse e domínio público. Contudo, a efetividade da gestão do parque se encontra em efetividade pouco satisfatória, deficientes em insumos e processos, na definição fundiária, de um modo geral apresentando certo grau de vulnerabilidade e baixa participação da comunidade no processo decisório local. Segundo Oliveira et al. (2008), o município de Viçosa do Ceará seria o município da serra com maior potencial de planejamento turístico, inclusive a revisão da política nacional de Turismo, por intermédio do PRODETUR-NE, habilitou a região da Ibiapaba a participar na captação de recursos desse programa.

Os municípios de Ibiapina e Ipu não haviam emergido na análise descendente, da classe 3, sendo citados na neste momento das classes, Ibiapina obteve uma frequência da aparição de f 59 e Ipu f18. Isso 
evidencia que o primeiro se mantém como prioridade do planejamento regional dentre os municípios ibiapabanos e faz parte do território, enquanto o segundo estaria em condições de desigualdade em reconhecimento territorial como composição do grupo de municípios e consequentemente perdendo preferência em detrimento dos demais municípios da Ibiapaba.

Percebe é que a cidade de Ipu acaba por ser um entroncamento, entre duas macrorregiões administrativas, com sedes nas cidades de Crateús e Sobral. Este fator acaba por dissipar a atenção pelos serviços públicos, o poder público faz recortes situacionais sem continuidade, acabam por excluir o município de Ipu em território ibiapabano.

A partir destas compilações pontua-se que a identificação territorial supera a individualização dos municípios e o planejamento regional para a geração de emprego e renda pretende se estabelecer em função da atividade turística, mesmo que a fruticultura, agricultura familiar produção de flores sejam atividades econômicas presentes na sustentabilidade econômica da Ibiapaba, como validação desta percepção a palavra agrícola e agrário.

\section{Dimensões Ambiental e Ecológica}

A região da Ibiapaba depende do equilíbrio na exploração dos recursos, devido à vinculação econômica relacionada à produção agrícola e ao turismo. Caso não haja a manutenção dos ciclos naturais a sustentabilidade regional estará comprometida (REZENDE et al., 2016).

O turismo da Ibiapaba figura com 72,91 de x2 com 'área poderá ser capaz de suportar as pressões exercidas pela atividade turística desde que se sejam estabelecidas diretrizes relacionadas ao uso e ocupação nessa unidade', se repetindo em 72,65 'a atividade turística depende diretamente do meio natural', 56,90 'conciliar o uso turístico dos atrativos com as políticas de conservação ambiental', percebe-se nestes três segmentos de texto que os participantes do planejamento local tem a consciência da quantidade de recursos naturais necessários para a manutenção da atividade turística.

Esta preocupação não se atém por acaso, se dá em função da ausência de planejamento, de usos contínuos e de monitoramento inadequados a região sobre impacto do turismo, gerando alterações ecológicas e paisagísticas, principalmente nas trilhas de visitação em Ubajara, razão dos $84 \%$ das visitas na cidade. Onde tudo devia ser considerado, até mesmo riscos mais 'brandos' como (ARCE-GOMEZ et al., 2015).

O terceiro segmento descendente da Classe 4, com x² 129,86 reflete os conflitos hídricos 'capacidade cota e volume dos principais açudes monitorados pelo programa de gerenciamento de águas territoriais segundo as bacias hidrográficas açude do território' refere-se a uma preocupação da dimensão ecológica e ambiental. $\mathrm{O}$ armazenamento por meio do sistema aquífero (água subterrânea) e precipitação pluviométrica é acima da média do Estado do Ceará (que é região do semiárido nordestino) porém há na Ibiapaba o problema de redução do potencial hídrico que abastece a região em função do aumento do consumo humano e necessidade do recurso para a produção a partir da agricultura irrigada.

O abastecimento e o saneamento se agravam a perspectiva, que pode ser vista na descrição 'esgotamento, ligação, rede, sanitária, ausência'. Apenas 51,34\% dos domicílios têm acesso a água potável e 
14,26\% acesso ao esgotamento sanitário, um percentual do abastecimento se dá por poço artesiano e os dejetos armazenados em fossas sépticas, que requerem um planejamento espacial para a não contaminação dos lençóis freáticos que abastecem os poços, em que apenas nos municípios de Ipu, Carnaubal e Guaraciaba do Norte com estudos de águas subterrâneas (IPECE, 2016).

Considera-se o tema do bloco resíduos sólidos com 'a coleta e a destinação dos resíduos sólidos' é deficiente na região, visualiza-se que há no texto a sugestão de indicativo para esta demanda, sobre a temática há a Proposta de Regionalização para a Gestão Integrada de Resíduos Sólidos, desenvolvida antes do PERS, em 2012, a previsão era que a serra produzisse 106,1 t/d de resíduos domiciliares. Nele conta com previsão de proposta para a construção de 2 aterros sanitários, tendo Tianguá como um município sede, com unidades de compostagem e triagem, para o custo estimado de $\mathrm{R} \$ 12.373 .625,14$, neste documento excluise Ipu.

Como última prioridade da questão ambiental está a discussão sobre a existência de órgãos de fiscalização ambiental. Os municípios serranos seguem a legislação estadual e federal, sendo deficiente a distância física da sede do órgão não está na região. As dificuldades nos serviços de fiscalização ambiental estão no porte dos municípios (em população e área) e poder econômico. Manterem uma equipe multidisciplinar, conforme Lei complementar 140 de 8 de dezembro de 2011, necessita um investimento em pessoal especializado com elevado custo para o erário municipal, que na maior parte dos municípios serrando a manutenção da estrutura municipal depende do Fundo de Participação dos Municípios.

\section{Dimensões políticas (nacionais e internacionais)}

O primeiro segmento de texto representativo nesta Classe 1 com 83,08 está o 'acompanhamento e controle social de ações e políticas públicas voltadas para projetos produtivos e desenvolvimento sustentável dos municípios'. Neste segmento dois recortes são significantes para esta pesquisa, são eles: 'controle social' e 'desenvolvimento sustentável'. O controle social consolida-se como uma prerrogativa na manutenção do ciclo do planejamento estratégico no espaço público, nele se avaliam os resultados do projeto os impactos sobre a distribuição dos benefícios e dos custos (RODRIGUES, 2011; FERREIRA et al., 2018).

A crítica sobre a participação na elaboração dos documentos vem no segmento 66,80 "durante o processo de implementação da estratégia de desenvolvimento territorial os gestores públicos têm se mantidos ausentes são raros os eventos em que os prefeitos do território comparecem e quando acontece ficam apenas para os momentos de abertura" este comportamento pode refletir que os gestores podem não estar dispostos a transferir a autonomia e poder de decisão para comunidades e unidades territoriais, seguindo um planejamento impositivo e normativo de centralização da decisão (DINIZ, 2009; SILVEIRA et al., 2013)

Nas frases construídas na análise descendente se possibilita ver que para a conquista da sustentabilidade a conexão está no fortalecimento institucional e na coesão social. Com 60,81 "fortalecer a administração municipal com ações de capacitação e assistência técnica no planejamento e gestão territorial e ambiental apoiar o fortalecimento da atuação das organizações da sociedade civil envolvidas no 
planejamento territorial" sendo a capacitação uma das condições apontadas por Malheiros et al. (2008), para o engajamento social na formulação, implementação e avaliação de políticas públicas (SILVA et al., 2018).

São citadas as relações institucionais e delas podem-se compreender que são as relações fortalecidas no meio rural, possivelmente pela sólida associação sindical dos produtores da agricultura familiar nos municípios serranos, que chega a mais de 40mil sindicalizados citados a somatória dos municípios de Tianguá, Guaraciaba do Norte, Viçosa do Ceará, Ubajara e Ibiapina. A sigla 'ONU' e nas palavras 'humano, mundial, conferência' capta-se que há no território da Ibiapaba a noção de um mundo global, dos reflexos, direitos e deveres de uma comunidade com o mundo e vice-versa, amplitude que afasta a região de um isolamento.

Na cooperação internacional na institucionalidade local para preservação ambiental e na busca pela sustentabilidade e o desenvolvimento regional, visão que advém dos fundos financeiros para a realização do planejamento regional da Ibiapaba advirem dos os organismos internacionais, inclusive citados nos planos, na busca por melhorias de países em desenvolvimento (SACHS, 1986b).

\section{CONCLUSÕES}

Considera-se o planejamento regional da Ibiapaba uma valiosa ferramenta de diagnóstico e definição de prioridade, mesmo com interesses conflitantes e demandas profundas. São documentos formais amparados pela construção coletiva com de metodologias de elaboração no modelo bottom-up, mesmo tendo partindo de organizações formais e do poder público (BROSE, 2014)

As flutuações dos conteúdos dos planos perpassam por conteúdos disciplinares que trazem textos técnicos e documentos descritos em contextos político-territoriais. Ao longo de todos os planos foram vistos modelos de multidisciplinaridade de áreas conhecimento e nas multidimensionalidades da sustentabilidade (SACHS, 2009).

Os municípios pactuantes dos planos sofreram variações de acordo com a temática (ambiental, turístico, rural), área de influência geográfica, onde em nenhum dos planos contemplou os nove municípios da região da Ibiapaba. Atribui-se este fator, além anterioridade dos planos (até o ano de 2014), à definição da área de planejamento regional ter se dados apenas em 2015 (define os nove municípios). Como também a identidade regional que muitas vezes incluir somente os municípios que em sua totalidade estão em cima do planalto, excluindo-se o município de Ipu e por sua vez priorizando Tianguá (IPECE, 2015).

O PMPNU - encarte 6 - Planejamento - 2002 não utiliza a sequência do modelo multidimensional até por ser outro tipo de documento técnico legal, parte de um plano de manejo. A sustentabilidade descrita nele é uma questão prioritária, voltada à preocupação com a pressão da variável de crescimento econômico e sistemas de produção sobre a unidade (SANCHS, 2009).

O PDIR Vale do Coreaú Ibiapaba - 2004 contemplaram sustentabilidade, competitividade e qualidade de vida. Estabelece-se ações de infraestrutura física, social e ambiental. O PDSRT - 2009 contempla as dimensões da sustentabilidade: políticas públicas, infraestrutura, economia e sustentabilidade, turismo, capacidade empresarial, monitoramento, social e cultural, valoriza o patrimônio natural e sociocultural e viabilize atividades econômicas inclusivas, dinâmicas e inovadoras, para a elevação da qualidade de vida da 
população.

O PTDRS 2011 segue a vertente do protagonismo da participação popular e do desenvolvimento territorial rural sendo o único documento que a cita especificamente: "Um novo projeto para o Brasil Rural deve ter um enfoque territorial de desenvolvimento da sociedade, que contemple as várias dimensões de sustentabilidade (econômica, social, política, tecnológica, cultural e ambiental)" (PTDRS, 2011), não aponta a dimensão política (internacional), com nenhuma citação a parcerias, a cooperação ou a transferência tecnológica com organismos internacionais.

O Manual de Operações do Programa de Desenvolvimento do Turismo Nacional - 2012 não tem como objetivos específicos a região da Ibiapaba, pontua na seleção de área a Chapada da Ibiapaba, dentre os componentes para a região: o produto turístico, a promoção e comercialização, o fortalecimento industrial, a infraestruturas e acesso a destinos, serviços básicos e a gestão ambiental.

O PDITS 2014 traz uma releitura e atualização do PDIR 2004 traz como requisito básico o desenvolvimento turístico sustentável que é ter um ambiente natural preservado e uma comunidade receptora integrada, favorecida econômica e socioculturalmente. Sobre a sustentabilidade em uma avaliação ex post as prioridades as quatro dimensões referenciadas em menor número foram: cultural, ambiental e política (nacional e internacional). A dimensão ambiental estaria em uma relação próxima com a dimensão ecológica, aproximando-se como área prioritária para a Ibiapaba.

A dimensão cultural, não foi evidente enquanto número de citações, contudo, considera-se que para se definir preferências em políticas públicas um dos requisitos estão os valores sociais compartilhados e não poderiam ser negligenciados, que pode ser visto nas construções das prioridades nos dendogramas de classes com um requisito vinculado à questão cultural e territorial na busca por unidade coletiva para a região (ARCEGOMEZ et al., 2015).

A dimensão política, está contemplada no primeiro segmento de texto da Classe 5 , "gestão e avaliação de política", no contexto de ações de saúde pública (SACHS, 1993). A dimensão política (internacional) foi identificada nos planos de 2004, 2012 e 2014, esclarece-se que nestes planos a elaboração dos documentos foram contrapartidas do Estado e dos municípios para financiamento do BIRD/Banco Internacional para Reconstrução e Desenvolvimento - Banco Mundial (SCHINDLER et al., 2018).

Por fim, as prioridades sociais voltaram-se para saúde e educação, as ambientais estão na questão hídrica, na destinação dos resíduos sólidos e na existência e fiscalização de órgãos ambientais. Requisitos básicos da sustentabilidade e que trazem reflexos para a sustentabilidade turística, posta como atividade econômica condicional ao avanço da sustentabilidade disposta pela comunidade.

\section{REFERÊNCIAS}

ARAÚJO SOBRINHO, F. L. A.; ALVES, I. C. S.; VIEIRA, P. L. M. Uma análise geográfica do plano de desenvolvimento turístico de Cavalcante-Goiás. Boletim de Geografia, v.33, n.3, p.31-45, 2015

ARCE-GOMEZ, A.; DONOVAN, J. D.; BEDGGOOD, R. E.. Social impact assessments: Developing a consolidated conceptual framework. Environmental Impact Assessment Review, v.50, p.85-94, 2015. DOI:

http://doi.org/10.1016/j.eiar.2014.08.006

BROSE, M. E.. Inovação na gestão pública subnacional: reflexões sobre a estratégia de desenvolvimento do Acre. Rev. Adm. Pública, v.48, n.2, p.277-294, 2014. 
CAMARGO, B. V.; JUSTO, A.. IRAMUTEQ: um software gratuito para análise de dados textuais. Temas em psicologia, v.21, n.2, p.513-518, 2013.

CAVALCANTI, C.. Sustentabilidade da Economia: paradigmas alternativos de realização econômica. In: CAVALCANTI, C.. Desenvolvimento e Natureza: estudos para uma sociedade sustentável. Recife: FUNDAJ, 1994.

CAVALCANTI, C.. Sustentabilidade: mantra ou escolha moral? Uma abordagem ecológico-econômica. Estudos Avançados, São Paulo, v.26, n.74, p.35-50, 2012.

CHEN, B.; CHEN, S.. Eco-indicators for urban metabolism. Ecological Indicators, v.47, p.5-6, 2014.

CARR, C.; BECKER, T.; EVRARD, E.; NIENABER, B.; ROOS, U.; MCDONOUGH, E.; HESSE, M.; KRUEGER, R.. Raising sustainability/Mobilizing sustainability: Why European sustainable urban development initiatives are slow to materialize/Territorial cohesion as a vehicle of sustainability/Sustainable urban development and the challenge of global air transport nodes and spatial integration/Distorted density: Where developers and nongovernmental organizations on sustainable urban development agree/Overcoming politics with markets?. The co-production of sustainable development in urban and regional planning, Planning Theory \& Practice, v.16, n.1, p.99-125, 2015.

DINIZ, C.. Celso Furtado e o desenvolvimento regional. Nova Econ., v.19, n.2, 2009.

FERREIRA, A.; BERNARDY, R.. Estudo e proposições para desenvolvimento estratégico do turismo no município de Itá (SC). Desenvolvimento Regional Em Debate, v.8, n.1, p.7089.

FRANCO, L. M. G.; REZENDE, D. A.; FIGUEIREDO, F. C.; NASCIMENTO, C.. Nível de divulgação eletrônica da contabilidade pública dos municípios do Paraná no ambiente da internet. Revista de Ciências da Administração, v.16, n.38, p.140-153, 2014.

HAMZA, C. H.; MARTINOS, O.; SCHWAB, S.. Ex post evaluation of urban development and social infrastructures final report: Ex post evaluation of Cohesion Policy programmes 2007-2013, focusing on the European Regional Development Fund (ERDF) and the Cohesion Fund (CF). In: WORK PACKAGE: EX POST EVALUATION OF URBAN DEVELOPMENT AND SOCIAL INFRASTRUCTURES, 10. Anais. 2016. DOI: http://doi.org/2014CE16BAT035

IPECE. Instituto de Pesquisa e Estratégia econômica do Ceará. As regiões de planejamento do estado do Ceará Textos para Discussão. N. 111. Fortaleza: IPECE, 2015.

IPECE. Instituto de Pesquisa e Estratégia econômica do Ceará. Limites e Regionalizações. Fortaleza: IPECE, 2016.

IPETURIS. Instituto de Pesquisas, Estudos e Capacitação em Turismo. Estudos de mercado dos polos turísticos do prodetur nacional no estado do Ceará. Fortaleza: IPETURIS, 2011.
LAKATOS, E. M.; MARCONI, M. A.. Metodologia do Trabalho Científico: procedimentos básicos, pesquisa bibliográfica, projeto e relatório publicações e trabalhos científicos. São Paulo: Atlas, 1992.

MAGALHÃES, A. R.. Um estudo de desenvolvimento sustentável do nordeste semiárido. In: CAVALCANTI, C.. Desenvolvimento e Natureza: estudos para uma sociedade sustentável. Recife: FUNDAJ, 1994.

MALHEIROS, T. F.; COUTINHO, S. M. G.; PHILIPPI JUNIOR, A. Desafio do uso de indicadores na avaliação da sustentabilidade. In: Indicadores de sustentabilidade e gestão ambiental. Barueri: Manoele, 2012.

POMPILI, T.. Ex Post evaluation of local development strategies. In: EUROPEAN REGIONAL SCIENCE ASSOCIATION, 36. Anais. Switzerland, 1996

OLIVEIRA, A. F. S.; KHAN, A. S.; LIMA, P. V. P. S.; SILVA, L. M. R.. A sustentabilidade da agricultura orgânica familiar dos produtores associados à APOI (Associação dos Produtores Orgânicos da Ibiapaba-CE). In: SOBER, CONGRESSO DA SOCIEDADE BRASILEIRA DE ECONOMIA, ADMINISTRAÇÃO E SOCIOLOGIA RURAL, 46. Anais. Rio Branco, 2008.

OLIVEIRA, V.; PINHO, P.. Evaluation in Urban Planning: Advances and Prospects. Journal of Planning Literature, v.24, n.4, p.343-361, 2010.

PORTER, M. E.. Estratégia competitiva: técnicas para análise de indústrias e da concorrência. 7 ed. Rio de Janeiro: Campus, 1991.

RATINAUD, P.; MARCHAND, P.. Application de la méthode ALCESTE à de 'gros' corpus et stabilité des 'mondes lexicaux': analyse du 'CableGate' avec IRaMuTeQ. In: JOURNÉES INTERNATIONALES D'ANALYSE STATISTIQUE DES DONNÉES TEXTUELLES, 11. Anais. 2012. p.835-844.

RAUPP, F. M.; BEUREN, I. M.. Metodologia da pesquisa aplicável às ciências sociais. In: BEUREN, I. M.. Como elaborar trabalhos monográficos em contabilidade: teoria e prática. 3 ed. São Paulo: Atlas, 2006.

REIS, M. P.. Elaboração de indicadores de desenvolvimento sustentável aplicados à região do Litoral Norte do Estado de São Paulo e análise específica da cidade de Ubatuba. Dissertação (Mestrado em Ciências Ambientais) Universidade de Taubaté, Taubaté, 2013.

REZENDE, J. F. C.; SINAY, M. C. F.. Methodology for leading indicators on sustainable regional development. Rev. Adm. Pública, Rio de Janeiro, v.50, n.3, p.395-423, 2016.

RODRIGUES, C. K.. Avaliação econômica de projetos públicos: uma abordagem teórica e prática à luz das decisões de investimento do SEBRAE/RS. Dissertação (Mestrado em Economia do Desenvolvimento) - Pontifícia Universidade Católica do Rio Grande do Sul, Porto Alegre, 2011.

SACHS, I.. Caminhos para o desenvolvimento sustentável. Rio de Janeiro: Garamond, 2009.

SACHS, I.. Dicionário do desenvolvimento: guia para o conhecimento como poder. Petrópolis: Vozes, 2000. 
SACHS, I.. Espaços, tempos e estratégias de

desenvolvimento. São Paulo: Vértice, 1986a.

SACHS, I.. Ecodesenvolvimento crescer sem destruir. Terra dos Homens. São Paulo: Vértice, 1986b.

SACHS, I.. Estratégias de transição para o século XXI. In: BURSZTYN, M.. Para pensar o Desenvolvimento

Sustentável. São Paulo: Brasiliense, 1993.

SCHINDLER, J.; GRAEF, F.; KÖNIG, H. J.. Methods to assess farming sustainability in developing countries. Agron.

Sustain. Dev., v.35, p.1043-1057, 2015.

SERAFIM, C. H. M.. Análise da sustentabilidade da produção orgânica do município de Guaraciaba do Norte, Ceará: um estudo de caso. Dissertação (Mestrado em Economia Rural) Universidade Federal do Ceará, Fortaleza, 2007.
SILVA, J. F. B. A.; REBOUÇAS, S. M. D. P.; ABREU, M. C. S.; RIBEIRO, M. C. R.. Building a sustainable development index and spacial assessment of municipalities inequalities in the state of Ceará. Rev. Adm. Pública, v.52, n.1, p.149-168, 2018.

SILVEIRA, R. B.; HELLER, L. S.; REZENDE, S.. Identificando correntes teóricas de planejamento: uma avaliação do Plano Nacional de Saneamento Básico (Plansab). Rev. Adm. Pública, v.47, n.3, p.601-622, 2013.

STAHEL, A. W.. Capitalismo e entropia: os aspectos ideológicos de uma contradição e a busca de alternativas sustentáveis. In: CAVALCANTI, C.. Desenvolvimento e Natureza: estudos para uma sociedade sustentável. Recife: FUNDAJ, 1994. p.262.

A CBPC - Companhia Brasileira de Produção Científica (CNPJ: 11.221.422/0001-03) detém os direitos materiais desta publicação. Os direitos referem-se à publicação do trabalho em qualquer parte do mundo, incluindo os direitos às renovações, expansões e disseminações da contribuição, bem como outros direitos subsidiários. Todos os trabalhos publicados eletronicamente poderão posteriormente ser publicados em coletâneas impressas sob coordenação da Sustenere Publishing, da Companhia Brasileira de Produção Científica e seus parceiros autorizados. Os (as) autores (as) preservam os direitos autorais, mas não têm permissão para a publicação da contribuição em outro meio, impresso ou digital, em português ou em tradução. 